\title{
Incidence of cancer among welders, platers, machinists, and pipe fitters in shipyards and machine shops
}

\author{
S TOLA,' P-L KALliOMÄKI, ' E PUKKALA, ${ }^{2}$ S ASP,' M-L KORKALA \\ From the Institute of Occupational Health, ${ }^{\prime}$ and Finnish Cancer Registry, ${ }^{2}$ Helsinki, Finland
}

ABSTRACT The incidence of cancer in 12693 shipyard and machine shop male workers (1689 welders, 4308 platers, 6003 machinists, 693 pipe fitters) employed for at least one year between 1945 and 1960 was investigated in a retrospective cohort study. The welders had welded only mild steel and had not been exposed to hexavalent chromium containing fume. The follow up was $99.7 \%$ complete and the total number of person-years was 304682 . The incidence of cancer in 1953-81 was ascertained through the Finnish Cancer Registry. The observed numbers of cases of cancer were compared with the expected numbers based on regional urban rates. The smoking habits of the cohort were surveyed with a postal questionnaire sent to a sample of 961 workers. The smoking habits of the cohorts were similar and smoking was not more common than among the general population. The total number of cases of cancer was 611 (exp 629) among the shipyard workers and 376 (exp 388) among the machine shop workers. The incidence of lung cancer was increased among the shipyard workers (obs 227, exp 192). This excess was observed in all the worker groups and was most evident for the pipe fitters and platers. Among the machine shop workers, the incidence of lung cancer was lower than expected with the exception of the welders who had a slightly raised risk of lung cancer (obs 14, exp 10). The incidence of laryngeal cancer was slightly raised among the shipyard workers (obs 24, exp 20) but not in the machine shop workers. No excess risk was observed among the welders. The incidence of cancer of the prostate was increased among the machine shop workers (obs 39, exp $31)$ but not in the shipyard workers. The excess was statistically significant for the welders. No pronounced excess could be found for other types of cancer. Analysis by the duration or exposure showed that the excess of lung cancer in the shipyard workers was most evident during the last period of observation (1972-81). No other trends were obvious and the slight excess of lung cancer observed among the welders did not increase with increasing follow up time. No excess risk for mesothelioma was found. The small excess of lung cancer in welders could be due to chance. The fact that only a small and statistically insignificant excess of lung cancer could be found among this group of heavily exposed welders suggests that if the risk of lung cancer was associated with welding this risk must nowadays be low and probably too low to be unequivocally detected in most epidemiological studies.

Welding has been associated with a moderately increased risk of lung cancer in several epidemiological studies $^{1-18}$ but the evidence of the aetiological role of welding fumes is still uncertain ${ }^{1920}$ and in most studies the confounding effects of asbestos and smoking cannot be ruled out. Several other exposures in the metal industry may also be associated with an increased risk of cancer. Some have already been

Accepted II May 1987 shown to be carcinogenic to man, particularly some compounds of chromium and nickel. ${ }^{21} 22$ Examples of less definite exposures are the polycyclic aromatic hydrocarbons present in cutting oil mist. ${ }^{2324}$ In the shipbuilding industry exposure to asbestos seems to be generally accepted as the main cause of the recognised excess of lung cancer but the involvement of other factors is less clear. $32 \leqslant 26$

The present study was designed to investigate the possible association between welding and the incidence of cancer in shipyards and machine shops. 
Table 1 Distribution of subjects by main occupation

\begin{tabular}{lllllr}
\hline Workplace & Welders & Platers & Machinists & Pipe & fitters \\
\hline Shipyards & 1308 & 3274 & 2585 & 608 & 7775 \\
Machine shops & 381 & 1034 & 3418 & 85 & 4918 \\
Total & 1689 & 4308 & 6003 & 693 & 12693 \\
\hline
\end{tabular}

Platers and machinists were included in the study, primarily as a comparison group for welders but also for separate study of their risk of cancer. Pipe fitters were included in the study as the group most likely to indicate the maximum effect of asbestos at these workplaces.

\section{Material and methods}

Data were collected from the personnel registers of five shipyards and four machine shops in south-southwestern Finland on all men who had worked continuously for at least one year in the selected occupations between 1945 and 1960. Occupational titles have changed over the years and titles for the same type of work have differed at the workplaces. Accordingly assistants trained by the research team collected the data at the workplaces, applying strict rules in categorising workers by occupation. Special care was taken to collect the data in a manner that would help comparison of exposures to metal fumes.

Table 1 shows the distribution according to occupations, all of which were derived by combining several subcategories-for example, the platers were composed of 18 subcategories which were coded separately. Welders were the most homogeneous group, consisting of only three subcategories, welders, welder's assistants, and apprentices.

In terms of exposure to metal fumes welders represent the most heavily exposed workers, platers had some exposure, and the machinists only slight or no exposure. Pipe fitters had the highest exposure to asbestos.

To estimate the exposure, all the workplaces were visited by the industrial hygienist in the research team (P-L K) and the production history for the study period was scrutinised.

SHIP BUILDING

Ship building was an insignificant industry in Finland before the second world war. The welders working in two small shipyards numbered only a few dozen. Six big shipyards were established in 1945 to enable war indemnities to be paid. Ships formed an important part of the payments which had to be delivered by the end of 1952. The number of welders and workers in other occupations in the shipyards increased rapidly between 1945 and 1952. Several hundred ships of different types were built during that period. The ships were built partly from new materials and partly from old ships. Both riveting and welding techniques were used at the same time. The first totally welded ship was built in 1950. The development of welding electrodes was rapid in that period. The types of the first commercially available electrodes varied greatly. The use of basic coated electrodes started around 1948-50, and after 1950 all the Finnish shipyards have used mainly (more than $80 \%$ ) this basic coated electrode (OK 48.00). The consumption of rutile electrodes has been small. Although the coating material has seen considerable development, the changes have had little effect on fume emission.

The exposure conditions in 1945-52 were exceptional. In the early period the level of exposure to fumes in closed spaces in the ships, tankers, and in the machine shops may have occasionally exceeded even $100 \mathrm{mg} / \mathrm{m}^{3}$. Remarkable hygienic improvements have taken place since 1970. In the shipyards the welders did welding during the entire working period and the platers usually worked near welders in the same areas. The shipyard welders included in this study represent pure manual metal arc (MMA) mild steel (MS) welders.

Since the war indemnity period all the shipyards have built mostly new ships; less than $10 \%$ of the work has been repairing old ships. The main types of ships have been high technology vessels such as cargo ships for special purposes, ice breakers, passenger ships, dredgers, and oil recovery vessels.

The manner in which new ships are built has been and still is similar at all the shipyards. The mild steel blocks (new material) are first transported to the plate hall where welders and platers weld the largest blocks together. The large blocks are then transported to the dock (dry or floating) where the shell of the ship is constructed. The outfitting of the ship takes place after most of the welders and platers have moved on to another dock. Insulation is done during the outfitting when only a few welders work in the ship. Asbestos was used as an insulating material from about 1955 to the middle of 1970. Spraying of asbestos was common, unfortunately, environmental or occupational hygienic measurements of asbestos fibres in the shipyard areas are not available, but considering the 
construction procedures of new ships, the exposure of welders and platers to asbestos has not been heavy. Moreover, the insulating work with asbestos has been done mainly by small contractors and not by the shipyard employees.

Indirect evidence also suggests that the level of exposure to asbestos has not been high at the shipyards in Finland. The chest radiographs of 32 welders who had worked at two different yards in Helsinki and who represent the most heavily exposed workers showed no evidence of asbestos or pleura plaques. ${ }^{27}$ No asbestosis has been diagnosed among shipyard welders or platers in Finland.

Other occupational groups such as pipe and engine fitters, electricians, and cleaners who work in the ship during the outfitting have probably had heavier exposure to asbestos than welders and platers, whereas their exposure to welding fumes has been low. The machinists (including turners, planer operators, drillers, grinders, milling machine operators, press machine operators, and tool makers) work in separate halls at all shipyards. Therefore the exposure of this group to either fumes or asbestos has been negligible. The remanent magnetic field of 25 machinists from one shipyard included in this study measured by the magnetopneumography (MPG) did not differ from that of controls, being two decades lower than the remanent magnetic field of a typical shipyard welder and one decade lower than that of a typical fulltime grinder. ${ }^{27}$

\section{MACHINE SHOPS}

There were few machine shops in Finland before the second world war. The biggest were established between 1945 and 1952. The selection of products in the four different machine shops has varied flexibly over the years. Each workshop has specialised to some degree in certain types of products. The working time of most welders in the machine shops was divided roughly equally between plating and welding.

In the beginning the main welding technique was MMA/MS welding. The metal inert gas technique (MIG) became common in the early 1970 s. Now the MIG technique and flux core wire welding have replaced the MMA method in most tasks. Therefore those welders in the study who continued welding in the 1970s have been exposed also to MIG/MS fumes. Alloyed steel was also introduced to the machine shops in the 1970s. The consumption of stainless steel increased significantly between 1975 and 1980. The welding of mild steel (MS) and stainless steel (SS) takes place in the same hall. It was established, however, that the welders included in the present study were only very little or not at all exposed to stainless steel welding fumes. The stainless steel welding fume exposure in the machine shops included in this study has been carefully characterised in another study. ${ }^{28}$ Therefore, we may conclude that only a small part of the welders in the present study might have had a very low standby exposure to stainless steel welding fumes since 1970.

The consumption of asbestos was also estimated in the machine shops. Insulation with asbestos proved to be a minor task in all the factories compared with that in shipyards. Asbestos plates have been used to some extent for insulation but asbestos has not been sprayed.

The machinists in the workshops worked in a separate hall, as did the machinists at shipyards, and their work consisted of similar tasks.

MANUAL METAL ARC (MMA) AND METAL INERT GAS (MIG) MILD STEEL (MS) WELDING FUMES Welding fumes have complex chemical and physical structures. Transmission electron micrograph (TEM) of MMA/MS fume shows that the MMA/MS fume consists of different typical particle populations. The typical chemistry of MMA/MS fumes and the suggested compounds present in the MMA/MS fumes based on $x$-ray diffraction and electron diffraction studies (PL Kalliomäki et al, unpublished data) are shown in table 2 .

\section{FOLLOW UP}

The 12693 subjects of whom 7775 were shipyard workers and 4918 machine shop workers were followed up until death or to 31 December 1981. The data were confirmed in the National Population Register and, when necessary, in local population registers. Possible retirement or changes of job did not affect the follow up. Altogether 37 workers could not be traced. Fourteen who could not be identified in the population

Table 2 Elemental composition (W/O) of the manual metal arc (MMA) mild steel (MS) welding PL fumes; suggested chemical compounds in the fume (PL Kalliomäki et al, unpublished data)

\begin{tabular}{lll}
\hline & $\begin{array}{l}\text { Typical chemical } \\
\text { concentrations of } \\
\text { elements }\end{array}$ & $\begin{array}{l}\text { Identified chemical } \\
\text { compounds }\end{array}$ \\
\hline $\mathrm{Na}$ & $0 \cdot 5$ & $\mathrm{Ca} \mathrm{F}_{2}$ \\
$\mathrm{Mg}$ & $0 \cdot 3$ & $\mathrm{~K} \mathrm{Ca} \mathrm{F}_{3}$ \\
$\mathrm{Al}$ & $0 \cdot 1$ & $-\mathrm{Fe}_{3} \mathrm{O}_{3}$ \\
$\mathrm{Si}$ & 1 & $\mathrm{Fe}_{3} \mathrm{O}_{3}$ \\
$\mathrm{~K}$ & 8 & $\mathrm{Mn} \mathrm{Fe}_{2} \mathrm{O}_{4}$ \\
$\mathrm{Ca}$ & $0 \cdot 7$ & $\mathrm{Mn}_{3} \mathrm{O}_{4}$ \\
$\mathrm{~T}$ & 0.1 & $\mathrm{~K} \mathrm{Fe} \mathrm{F}_{3}$ \\
$\mathrm{Cr}$ & 0.01 & $\mathrm{Kn} \mathrm{F}_{3}$ \\
$\mathrm{Mn}$ & 4 & $\mathrm{Ca} \mathrm{Cq}_{3}$ \\
$\mathrm{Fe}$ & 7 & \\
$\mathrm{Ni}$ & 0.02 & \\
$\mathrm{Cn}$ & 0.03 & \\
$\mathrm{Zn}$ & 0.03 & \\
$\mathrm{Mo}$ & 0.05 & \\
$\mathrm{~Pb}$ & 0.5 & \\
\hline
\end{tabular}


registries at all were excluded from the study. Nineteen were lost to follow up after moving abroad to other than the Nordic countries and four who had moved to the Nordic countries could not be found in the registries there. The person-years for those lost to follow-up were calculated until the day of leaving the country. The total number of person-years was 181493 in the shipyards and 123189 in the machine shops.

The incidence of cancer up to 31 December 1981 was derived from the records of the Finnish Cancer Registry, which has virtually complete data of all the primary cancers diagnosed in Finland since 1953.29 Information was also obtained from the population based cancer registries of Sweden and Norway on the primary cancers of the workers who had emigrated to those countries. The cancer diagnoses were coded according to the 7th revision of the International Classification of Diseases (1967). ${ }^{30}$

The expected numbers of primary cancers were calculated by multiplying the age and calendar period specific numbers of person-years at risk in each subgroup by the corresponding cancer incidence rates based on figures of the urban population in the same geographical area. For the shipyard workers, these were the figures of the urban municipalities of the Uusimaa, and Turku and Pori counties, and for the machine shop workers those of the Kymi and Häme counties. The calendar periods for which the personyears and reference incidences were calculated were 1953-61, 1962-71, and 1972-81. The duration of follow up starting from 1 January 1953 or the date of entry in the cohort - whichever was latest - was used as an additional classifier of expected and observed numbers of cases. In some cases it was possible that one member of the cohort fulfilled the criteria of belonging to more than one subgroup - for example, he had worked at least one year as a welder and one year as a plater. In these (rare) cases the cancers and numbers of person-years were counted to all the occupational subgroups in question. The small effect of this type of "double counting" is further reduced by the fact that the total number of cancers includes also
Table 3 Observed (Obs) and expected (Exp) numbers, standardised incidence ratios (SIRs), and $95 \%$ confidence limits $(95 \% C L)$ of various cancer sites among shipyard workers

\begin{tabular}{lrrrr}
\hline Cancer type (ICD No) & Obs & \multicolumn{1}{c}{ Exp } & SIR & $95 \% C L$ \\
\hline Stomach (151) & 63 & $78 \cdot 8$ & 80 & $61-102$ \\
Rectum and colon (153-154) & 35 & $44 \cdot 1$ & 79 & $55-110$ \\
Nose (160) & 1 & $2 \cdot 7$ & 37 & $1-206$ \\
Larynx (161) & 24 & $20 \cdot 0$ & 120 & $77-179$ \\
Lung (162-163, & & & & \\
$\quad$ excl mesothelioma) & 227 & $192 \cdot 1$ & 118 & $103-135$ \\
Prostate (177) & 48 & $49 \cdot 2$ & 98 & $72-129$ \\
Urinary bladder (181) & 21 & $22 \cdot 9$ & 92 & $57-140$ \\
Skin (191) & 10 & $11 \cdot 5$ & 87 & $42-160$ \\
Hodgkin's disease & & & \\
$\quad$ and lymphomas (200-202) & 16 & $18 \cdot 2$ & 88 & $50-143$ \\
Leukaemia (204) & 19 & $16 \cdot 6$ & 114 & $69-179$ \\
Total & 611 & $629 \cdot 4$ & 97 & $90-105$ \\
\hline
\end{tabular}

some individuals with multiple cancers. Standardised incidence ratios (SIR) were obtained as ratios between the observed and expected numbers of cases, and $95 \%$ confidence limits were calculated. ${ }^{31}$

Because smoking is a major potential confounder in studies of cancer, smoking habits were inquired about by postal questionnaires from a stratified sample of the workers. To ensure a sufficient number of welders in the sample, the sample was drawn separately from welders and from machine shop workers. One third of the welders was selected randomly, and one machine shop worker was then selected for each welder in the sample. Smoking in the year 1956 (yes or no) and at the time of the inquiry-1981 (yes or no, stopped or not, amount smoked) was specifically asked. The year 1956 was chosen because there were previous data available for that year ${ }^{32}$ and it was near the midpoint of the exposure period. There had also been a general strike in Finland in 1956, which was clearly remembered by most people. A total of 961 questionnaires was sent out. Of this sample, 749 were alive and 212 had died. In the latter case the questionnaire was sent to the next of kin. A reply was received from $81.0 \%$ of the living workers and $77.4 \%$ from the next of kins.

Table 4 Person-years, observed (Obs) and expected (Exp) numbers, SIRs, and 95\% CL of all cancers for 1953-81 among shipyard and machine shop workers

\begin{tabular}{|c|c|c|c|c|c|c|c|c|c|c|}
\hline \multirow[b]{2}{*}{ Worker group } & \multicolumn{5}{|c|}{ Shipyard } & \multicolumn{5}{|c|}{ Machine shops } \\
\hline & $\begin{array}{l}\text { Person- } \\
\text { years }\end{array}$ & Obs & Exp & $S I R \%$ & $95 \% C L$ & $\begin{array}{l}\text { Person- } \\
\text { years }\end{array}$ & $O b s$ & $\overline{E x p}$ & $S I R \%$ & $95 \% C L$ \\
\hline $\begin{array}{l}\text { Welders } \\
\text { Platers } \\
\text { Machinists } \\
\text { Pipe fitters }\end{array}$ & $\begin{array}{l}34191 \\
82972 \\
60590 \\
15680\end{array}$ & $\begin{array}{r}78 \\
299 \\
224 \\
48\end{array}$ & $\begin{array}{r}78.9 \\
289.9 \\
251 \cdot 1 \\
49.4\end{array}$ & $\begin{array}{r}99 \\
103 \\
89 \\
97\end{array}$ & $\begin{array}{l}78-123 \\
92-116 \\
78-102 \\
72-129\end{array}$ & $\begin{array}{r}10990 \\
30252 \\
89529 \\
2250\end{array}$ & $\begin{array}{r}43 \\
115 \\
246 \\
9\end{array}$ & $\begin{array}{r}33.3 \\
116.0 \\
263.0 \\
12.0\end{array}$ & $\begin{array}{r}129 \\
99 \\
94 \\
75\end{array}$ & $\begin{array}{l}93-174 \\
82-119 \\
82-106 \\
34-142\end{array}$ \\
\hline Total & 181493 & 611 & $629 \cdot 4$ & 97 & $90-105$ & 123189 & 376 & $388 \cdot 3$ & 97 & $87-107$ \\
\hline
\end{tabular}


Table 5 Observed (Obs) and expected (Exp) numbers, $S R I s$, and $95 \%$ CL of various cancer sites among machine shop workers

\begin{tabular}{lrrrr}
\hline Cancer type (ICD No) & Obs & Exp & SIR & $95 \%$ CL \\
\hline Stomach (151) & 42 & $47 \cdot 5$ & 88 & $64-120$ \\
Rectum and colon (153-154) & 28 & $28 \cdot 1$ & 100 & $66-144$ \\
Nose (160) & 2 & $1 \cdot 3$ & 154 & $19-556$ \\
Larynx (161) & 8 & $11 \cdot 6$ & 69 & $30-136$ \\
Lung (162-163, excl mesothelioma) & 110 & $118 \cdot 8$ & 93 & $76-112$ \\
Prostate (177) & 39 & $30 \cdot 9$ & 126 & $90-173$ \\
Urinary bladder (181) & 19 & $14 \cdot 4$ & 132 & $79-206$ \\
Skin (191) & 11 & $7 \cdot 8$ & 141 & $70-252$ \\
Hodgkin's disease and lymphomas & 8 & $11 \cdot 1$ & 72 & $31-142$ \\
(200-202) & 9 & $9 \cdot 8$ & 92 & $42-174$ \\
Leukaemia (204) & 9 & & & \\
Total & 376 & $388 \cdot 3$ & 97 & $87-107$ \\
\hline
\end{tabular}

\section{Results}

The total number of cases of cancer among the shipyard workers was 611 , somewhat less than expected (629.4) (table 3). A slight excess of cancer was found for the platers (obs 299, exp 289.9) (table 4). In the machine shops (table 5) the observed number of cases of cancer was also smaller than the expected value (obs $376, \exp 388.3$ ) but there was a small excess of cancer in the group of welders (obs 43, exp 33.3).

The SIR for lung cancer was increased among the shipyard workers (obs 227, exp 192.1) (table 6). This excess was found in all the worker groups and was most evident for the pipe fitters (obs 23, exp 15.0) and the platers. The small excess of lung cancer observed among welders (obs 27, exp 23.5) was not statistically significant. Among the machine shop workers, the SIR for lung cancer was smaller than expected for all the occupational groups other than welders. The small excess among welders (obs 14, exp 10.4) was not statistically significant. There were only two cases of malignant mesothelioma in the whole study; both subjects were machinists, one from a shipyard (exp $1 \cdot 13)$ and the other from a machine shop (exp 0.36).

The SIR for cancer of the larynx was higher among the shipyard workers and lower among the machine shop workers than expected but neither of these differences were statistically significant (table 7). No excess risk was found among the welders.

The SIR for cancer of the prostate was increased in the machine shop workers (obs 39, exp 30.9) but not in the shipyard workers (table 7). By occupation, the excess was statistically significant for the welders in the machine shops (obs 7, exp 2.5, p < 0.05).

For cancer of the urinary bladder the SIR was close to expected in the shipyard workers but somewhat higher in the machine shop workers. The excess was not statistically significant (table 7).

The SIR for leukaemia was slightly raised among the shipyard workers (table 7). The excess was most evident for the machinists but it was not statistically significant. No excess was found in the machine shop workers.

No pronounced excess was found for other types of cancer (table 8).

The incidence of cancer by occupation was also studied separately for three periods, 1953-61, 196271 , and 1972-81. The total number of cases of cancer in shipyard workers was less than expected during 1953-61 and 1962-71 and slightly raised for 1972-81 (obs 348, exp 321.3). The same phenomenon could be observed also for the machine shop workers but was less evident in 1972-81 (obs 221, exp 210.6).

The excess risk of lung cancer observed in the shipyard workers was most evident for 1972-81 (obs $126, \exp 100.3, \mathrm{p}<0.05$ ) but the incidence was higher than expected also for 1953-61 and 1962-71. No other trends were evident in the total shipyard material. In the machine shops there was no clear trend for any of the cancers.

The small excess of lung cancer observed among the welders in shipyards showed no clear trend, but the SIR was highest in the middle period and about the same as expected during the other periods. No trend could be observed for the machine shop welders, either. The cases of cancer of the prostate among the machine shop welders accumulated to 1972-81 (obs 5, $\exp 1.99, \mathrm{p}<0.05)$.

The excess risk of lung cancer observed among the

Table 6 Observed (Obs) and expected (Exp) numbers, SIRs, and 95\% CL of all cancer (excl mesothelioma) for 1953-8I among shipyard and machine shop workers.

\begin{tabular}{|c|c|c|c|c|c|c|c|c|}
\hline \multirow[b]{2}{*}{ Worker groups } & \multicolumn{4}{|c|}{ Shiplards } & \multicolumn{4}{|c|}{ Machine shops } \\
\hline & $O h s$ & Exp & $S I R$ & $95 \% C L$ & $\overline{O h s}$ & Exp & $S I R$ & $95 \% C L$ \\
\hline $\begin{array}{l}\text { Welders } \\
\text { Platers } \\
\text { Machinsts } \\
\text { Pipe fitters }\end{array}$ & $\begin{array}{r}27 \\
103 \\
87 \\
23\end{array}$ & $\begin{array}{l}23 \cdot 5 \\
88 \cdot 5 \\
77 \cdot 5 \\
15 \cdot 0\end{array}$ & $\begin{array}{l}115 \\
116 \\
112 \\
153\end{array}$ & $\begin{array}{l}76-167 \\
95-141 \\
90-138 \\
97-230\end{array}$ & $\begin{array}{r}14 \\
34 \\
67 \\
2\end{array}$ & $\begin{array}{r}10.4 \\
36.1 \\
79.7 \\
3.8\end{array}$ & $\begin{array}{r}135 \\
94 \\
84 \\
53\end{array}$ & $\begin{array}{r}74-226 \\
65-132 \\
65-107 \\
6-190\end{array}$ \\
\hline Total & 227 & $192 \cdot 1$ & 118 & $103-135$ & 110 & 118.8 & 93 & $76-112$ \\
\hline
\end{tabular}


Table 7 Observed (Obs) and expected (Exp) numbers, SIRs, and 95\% CL of cancer of the larynx, prostate, and urinary bladder, and ( leukaemia for 1953-81 among shipyard and machine shop workers

\begin{tabular}{|c|c|c|c|c|c|c|c|c|c|c|c|c|c|c|c|c|}
\hline & \multicolumn{4}{|c|}{ Larynx } & \multicolumn{4}{|c|}{ Prostate } & \multicolumn{4}{|c|}{ Urinary bladder } & \multicolumn{4}{|c|}{ Leukaemia } \\
\hline & $O b s$ & Exp & $S I R$ & $95 \% C L$ & $O b s$ & Exp & $S I R$ & $95 \% \mathrm{Cl}$ & Obs & $\operatorname{Exp}$ & $S I R$ & $95 \% C L$ & Obs & Exp & $S I R$ & $95 \%$ \\
\hline \multicolumn{17}{|c|}{ Shipyard workers } \\
\hline Welders & 2 & $2 \cdot 7$ & 74 & $9-268$ & 7 & $4 \cdot 3$ & 163 & $65-335$ & 2 & $2 \cdot 8$ & 71 & $9-258$ & 2 & $2 \cdot 2$ & 91 & $11-32$ \\
\hline Platers & 14 & $9 \cdot 2$ & 152 & $83-255$ & 26 & $22 \cdot 8$ & 114 & $74-167$ & 11 & $10 \cdot 6$ & 104 & $52-186$ & 9 & $7 \cdot 6$ & 118 & $54-22$ \\
\hline Machinists & 8 & $7 \cdot \overline{8}$ & 103 & $44-202$ & 12 & $21 \cdot 3$ & 56 & 29-98 & 9 & $9 \cdot 3$ & 97 & $44-184$ & 9 & $6 \cdot 4$ & 141 & $64-26$ \\
\hline Pipe fitters & 2 & $1 \cdot 6$ & 125 & $15-452$ & 8 & $3 \cdot 7$ & 216 & $93-426$ & 0 & $1 \cdot 8$ & - & $0-166$ & 1 & $1 \cdot 3$ & 77 & $2-42$ \\
\hline Total & 24 & $20 \cdot 0$ & 120 & $77-179$ & 48 & $49 \cdot 2$ & 98 & $72-129$ & 22 & $22 \cdot 9$ & 96 & $60-145$ & 19 & $16 \cdot 6$ & 114 & $69-17 c$ \\
\hline \multicolumn{17}{|c|}{ Machine shop workers } \\
\hline Welders & 1 & $1 \cdot 0$ & 100 & $2-557$ & 7 & $2 \cdot 5$ & 280 & $113-557$ & 2 & $1 \cdot 3$ & 154 & $19-556$ & 1 & $0 \cdot 8$ & 125 & 3-696 \\
\hline Platers & 3 & $3 \cdot 4$ & 88 & $18-258$ & 14 & $9 \cdot 9$ & 141 & $77-237$ & 4 & $4 \cdot 3$ & 93 & $25-238$ & 3 & $2 \cdot 8$ & 107 & $22-313$ \\
\hline Machinists & 5 & $7 \cdot 9$ & 63 & $21-148$ & 19 & $20 \cdot 3$ & 94 & $56-146$ & 14 & $9 \cdot 8$ & 143 & $78-240$ & 6 & $6 \cdot 7$ & 90 & $33-195$ \\
\hline Pipe fitters & 0 & $0 \cdot 3$ & $\cdots$ & 0-999 & 2 & $1 \cdot 2$ & 167 & $20-602$ & 1 & $0 \cdot 5$ & 200 & $5-1114$ & 0 & $0 \cdot 3$ & - & $0-999$ \\
\hline Total & 8 & $11 \cdot 6$ & 69 & $30-136$ & 39 & 30.9 & 126 & $90-173$ & 19 & $14 \cdot 4$ & 132 & $79-206$ & 9 & $9 \cdot 8$ & 92 & $42-174$ \\
\hline
\end{tabular}

shipyard platers was most evident in 1953-61 (obs 19, exp 12.6) but was observed during all three periods. The cases of laryngeal cancer were more common during 1962-71 and 1972-81 and the excess was highest during 1962-71 (obs 7, exp 3·5). The excess risk of lung cancer observed among the shipyard machinists was observed only in 1972-81 (obs 53, exp 38.4). The same was true for the pipe fitters (obs 15, exp 8.0).

No trends were detected among the platers. The cases of stomach cancer accumulated to 1972-81 among the machinists in the machine shops; this excess was statistically significant (obs 23 , exp 14.8, p<0.05), although the incidence of stomach cancer during the total observation period was the same as expected.

To estimate the effect of possible latency period on the incidence of lung cancer the results were analysed according to the follow up period since first exposure (table 9). No clear trend was evident.
The smoking habits of the shipyard and machine shop workers were similar (table 10). The percentage of current smokers at the time of the inquiry was slightly smaller among the shipyard workers. The smoking habits in 1956 were similar for both groups and close to the prevalence among the pulp and paper workers $(55 \%)$ who answered an identical questionnaire in another study. ${ }^{33}$ The prevalence of smokers among the whole male population in Finland was about $60 \%$ around 1960 and decreased thereafter to about $30 \%$ around $1980 .{ }^{34}$ Thus the smoking habits of this cohort roughly correspond to the average Finnish smoking habits. When welders were compared with other occupations, the prevalence of smoking was similar among welders and other occupational groups in shipyards $(28 \%)$ and somewhat more common among machine shop welders than non-welders $(38 \%$ v $34 \%)$.

Table 8 Observed (Obs) and expected (Exp) numbers, SIRs, and 95\% CL of cancer of the stomach, rectum and colon, skin, and lymphomas 3. and Hodgkin's disease for 1953-81 among shipyard and machine shop workers

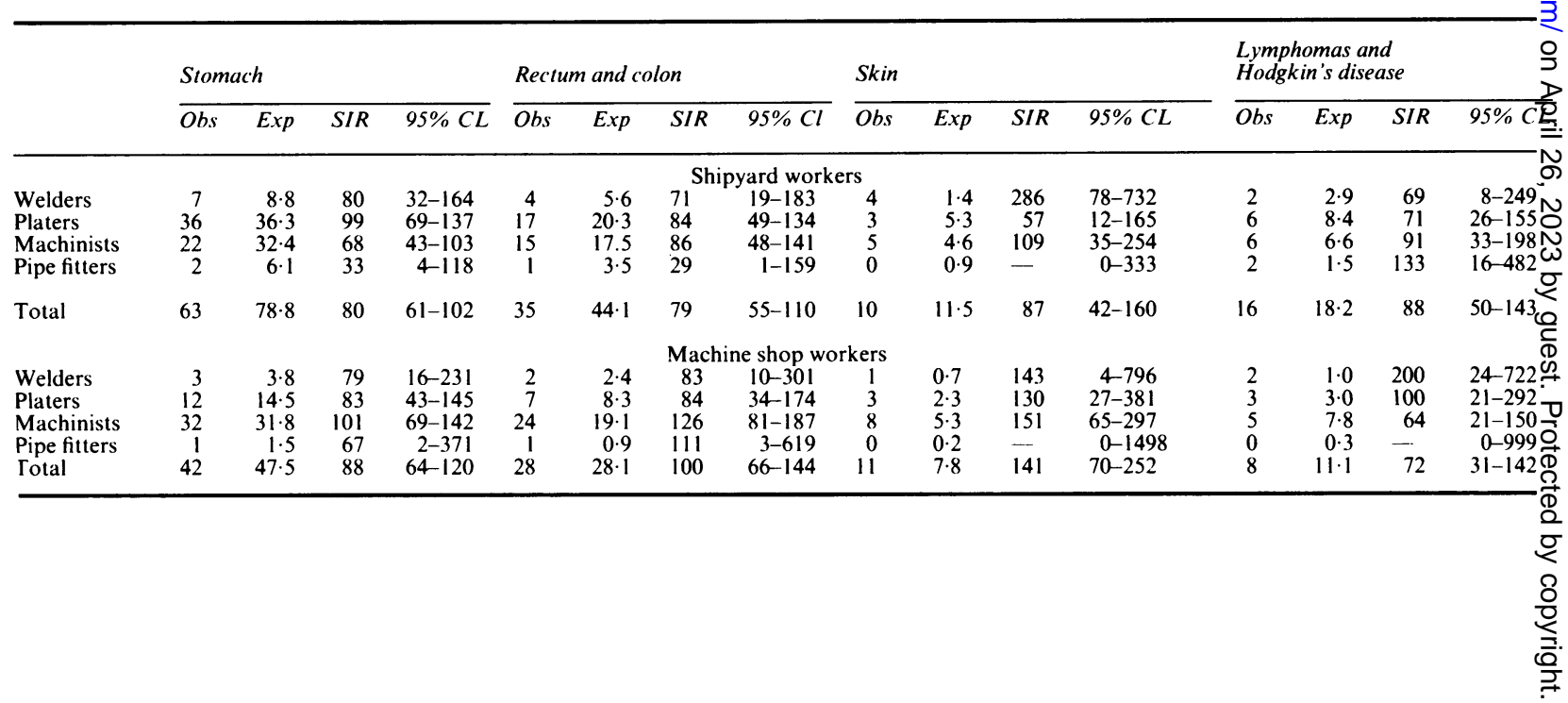


Table 9 Observed (Obs) and expected (Exp) numbers and SIRs of cases of lung cancer (excluding mesothelioma) according to time since first exposure

\begin{tabular}{|c|c|c|c|c|c|c|c|c|c|c|c|c|c|c|c|}
\hline & \multicolumn{3}{|c|}{$\begin{array}{l}\text { Follow up period (years) } \\
1-9\end{array}$} & \multicolumn{3}{|c|}{$10-19$} & \multicolumn{3}{|c|}{$20-29$} & \multicolumn{3}{|l|}{$\geqslant 30$} & \multicolumn{3}{|c|}{ Total } \\
\hline & $O b s$ & $\operatorname{Exp}$ & SIR & $O b s$ & $\operatorname{Exp}$ & SIR & $O b s$ & $\operatorname{Exp}$ & SIR & Obs & $\operatorname{Exp}$ & SIR & Obs & $\operatorname{Exp}$ & $S I R$ \\
\hline $\begin{array}{l}\text { Welders } \\
\text { Platers } \\
\text { Machinists } \\
\text { Pipe fitters }\end{array}$ & $\begin{array}{l}2 \\
\overline{2} \\
2\end{array}$ & $\begin{array}{l}0.9 \\
3 \cdot 8 \\
3 \cdot 9 \\
0 \cdot 8\end{array}$ & $\begin{array}{l}225 \\
- \\
51 \\
250\end{array}$ & $\begin{array}{r}3 \\
19 \\
18 \\
4\end{array}$ & $\begin{array}{r}4 \cdot 4 \\
16 \cdot 9 \\
15 \cdot 7 \\
3 \cdot 1\end{array}$ & $\begin{array}{l}\text { Shi } \\
68 \\
112 \\
115 \\
129\end{array}$ & $\begin{array}{l}\text { ard wo } \\
15 \\
39 \\
34 \\
8\end{array}$ & $\begin{array}{l}\text { cers } \\
11.0 \\
35.5 \\
29.3 \\
6.1\end{array}$ & $\begin{array}{l}136 \\
110 \\
116 \\
132\end{array}$ & $\begin{array}{r}7 \\
45 \\
33 \\
9\end{array}$ & $\begin{array}{r}7 \cdot 2 \\
32 \cdot 3 \\
28 \cdot 5 \\
5 \cdot 0\end{array}$ & $\begin{array}{r}97 \\
139 \\
116 \\
180\end{array}$ & $\begin{array}{r}27 \\
103 \\
87 \\
23\end{array}$ & $\begin{array}{l}23 \cdot 5 \\
88 \cdot 5 \\
77 \cdot 5 \\
15 \cdot 0\end{array}$ & $\begin{array}{l}115 \\
116 \\
112 \\
154\end{array}$ \\
\hline Total & 4 & $7 \cdot 8$ & 51 & 42 & $36 \cdot 4$ & 115 & 89 & $76 \cdot 6$ & 116 & 92 & $71 \cdot 4$ & 129 & 227 & $192 \cdot 1$ & 118 \\
\hline $\begin{array}{l}\text { Welders } \\
\text { Platers } \\
\text { Machinists } \\
\text { Pipe fitters }\end{array}$ & $\begin{array}{l}- \\
1 \\
-\end{array}$ & $\begin{array}{l}0 \cdot 5 \\
1 \cdot 5 \\
2 \cdot 2 \\
0 \cdot 2\end{array}$ & $\begin{array}{l}- \\
67 \\
46 \\
-\end{array}$ & $\begin{array}{r}3 \\
6 \\
7 \\
-\end{array}$ & $\begin{array}{r}1.9 \\
5.6 \\
10.5 \\
1.0\end{array}$ & $\begin{array}{c}\text { Mach } \\
162 \\
108 \\
67 \\
-\end{array}$ & $\begin{array}{c}\text { e shop } \\
6 \\
10 \\
20 \\
2\end{array}$ & $\begin{array}{c}\text { orkers } \\
4.1 \\
11.9 \\
25.0 \\
1.5\end{array}$ & $\begin{array}{r}147 \\
84 \\
80 \\
135\end{array}$ & $\begin{array}{r}5 \\
17 \\
39 \\
-\end{array}$ & $\begin{array}{r}3 \cdot 5 \\
17 \cdot 1 \\
42 \cdot 1 \\
1 \cdot 1\end{array}$ & $\begin{array}{r}143 \\
99 \\
93 \\
-\end{array}$ & $\begin{array}{r}14 \\
34 \\
67 \\
2\end{array}$ & $\begin{array}{r}9 \cdot 9 \\
36 \cdot 1 \\
79 \cdot 7 \\
3 \cdot 8\end{array}$ & $\begin{array}{r}142 \\
94 \\
84 \\
53\end{array}$ \\
\hline Total & 2 & $2 \cdot 5$ & 79 & 13 & $15 \cdot 6$ & 83 & 34 & $38 \cdot 7$ & 88 & 61 & 61.9 & 99 & 110 & 118.8 & 93 \\
\hline
\end{tabular}

\section{Discussion}

When assessing the results of an occupational cohort study such as the present one, three main issues should be considered. Firstly, how the exposure was defined; secondly, how the follow up and ascertainment of the disease of interest was performed; and thirdly, what possible confounding factors could affect the results and how they could be controlled.

The assessment of exposure in the present study was mainly qualitative and based on available documents as well as several interviews of both present and former workers and foremen. Special attention was paid to the completeness of the records at the workplace. Analysis of the data showed no inconsistencies, which would suggest that, for example, some part of the work force had been omitted from the study. The collection of data was performed by trained research assistants and not by personnel of the workplace. The inclusion criteria for workers were set before collecting the data and they were based-as was the subsequent sub-

Table 10 Smoking habits of the shipyard and machine shop workers. Smoking in 1956 and 1981 and the lifetime smoking of the dead workers

\begin{tabular}{|c|c|c|c|c|c|c|c|c|}
\hline & \multicolumn{4}{|c|}{ Shiplard workers } & \multicolumn{4}{|c|}{ Machine shop workers } \\
\hline & $\overline{1981}$ & $\%$ & $\begin{array}{l}1956 \\
\text { No }\end{array}$ & $\%$ & $\begin{array}{l}1981 \\
\text { No }\end{array}$ & $\%$ & 1956 & $\%$ \\
\hline & \multicolumn{8}{|c|}{ Workers alive at the time of the inquiry } \\
\hline Non-smokers & 101 & 26 & 166 & 42 & 55 & 27 & 90 & 43 \\
\hline Smokers & 98 & 25 & 228 & 58 & 63 & 31 & 119 & 57 \\
\hline Stopped smoking & 184 & 48 & -- & -- & 84 & 42 & - & - \\
\hline Total & 383 & 100 & 394 & 100 & 202 & 100 & 209 & 100 \\
\hline & \multicolumn{8}{|c|}{ Dead workers } \\
\hline Non-smokers & 29 & 27 & 35 & 34 & 7 & 15 & 12 & 27 \\
\hline Smokers & 78 & 73 & 69 & 66 & 40 & 85 & 33 & 73 \\
\hline Total & 107 & 100 & 104 & 100 & 47 & 100 & 45 & 100 \\
\hline
\end{tabular}

grouping - on thorough scrutiny with old foremen of the previous working conditions and occupational title listings. Therefore, we believe that the definition of exposure in terms of occupational groups is as reliable as it is possible to achieve in studies such as this.

The follow up in this study was $99.7 \%$ complete. Only 14 workers could not be traced at all and removing them from the study should not affect the reliability of the results. With the exception of four, all workers who could be identified could also be traced in Finland or the other Nordic countries. Even combined with those 19 workers who moved elsewhere and could not be traced, the number of subjects lost to follow up was only $0 \cdot 3 \%$.

The diagnosis of cancer in this study was based on the information available from the Finnish Cancer Registry. The reporting of a new case of cancer to the cancer registry is obligatory in Finland and the other Nordic countries. The quality of the diagnoses of cancer and the completeness of the data are continuously monitored. ${ }^{29} 35$ Consequenctly, the diagnostic quality of the registers is good for the purposes of an epidemiological study.

Age is a major determinant of cancer, and it was accounted for in the analyses by five year age categories. The calculation of the expected values was performed for 10 year intervals separately, which should eliminate the effect of secular trends accurately enough for the purpose of this study.

The so called healthy worker effect ${ }^{36}{ }^{37}$ cannot be eliminated from a study such as the present one and, unfortunately, no reliable quantitative estimate of its impact is available. Analysis by the follow up and exposure period should help in controlling the healthy worker effect, which should be smallest for those with the longest exposure period and follow up. It is also known that the healthy worker effect is a smaller 
problem in studies of cancer than in some others-for example, of coronary heart disease. Irrespective of the magnitude of the healthy worker effect, it makes the interpretation of statistical significance testing problematical. More attention should therefore be paid to the consistency and direction of the results than to the conventional significance levels. In this study several occupations with different exposure but similar social background have been followed up. Consequently, the comparison between different occupations within the study provides one possibility to assess the relative importance of exposure and other factors. These internal comparisons should be practically unaffected by the healthy worker effect.

Smoking is a major potential confounder in studies of cancer, especially when lung cancer is found in small excess as in the present study. This is especially important since some authors have reported that welders smoke more than the general population. ${ }^{1238} 39$ There were no reliable data available on the smoking habits of the workers in the records, and therefore an attempt was made to evaluate the smoking habits by postal questionnaires. Several problems are encountered in an approach such as this, ${ }^{40}$ but because we had access to the results of an identical inquiry of a parallel epidemiological study on pulp and paper workers ${ }^{3}$ we thought that the questionnaire gave reasonably reliable information on the relative smoking frequencies of the different groups of workers. It seems that the smoking habits of the study population did not differ from those of the general population in a way that could explain the excess of lung cancer. Moreover, within the study the groups of workers with an excess of lung cancer did not smoke more than the groups without such excess. In fact, smoking was slightly less prevalent in shipyards than in machine shops. Therefore it is valid to consider occupational factors as a possible cause of the excess of lung cancer that has been found.

The main finding of this study was the increased risk of lung cancer (SIR 118, p < 0.05) among the shipyard workers. The most probable eplanation for this finding is exposure to asbestos. The excess was most prominent (SIR 153) for the pipe fitters, who were considered to be the most exposed group in terms of possible asbestos exposure. The excess risk of lung cancer for this group was lower than that reported in most epidemiological studies on shipyard workers. According to the information that we have been able to collect of exposure to asbestos in Finnish shipyards it seems that asbestos was not commonly used in the Finnish shipbuilding industries and the way of using it for special purposes has kept down the number of exposed workers. Furthermore, the most difficult asbestos insulation work was performed mainly by small specialised companies and not by shipyard employees. Therefore, the pipe fitters at the shipyard were probably not as much exposed as in some other studies. The fact that risk of mesothelioma was not increased also speaks in favour of relatively low exposure to asbestos.

Regarding exposure to metal fumes, the results are inconclusive. There was a small increase in the incidence of lung cancer among the welders in the shipyard (SIR 115) as well as the machine shops (SIR 135) but it was not statistically significant. Excess lung cancer was also observed for the platers in the shipyards but not in the machine shops. Since the platers are exposed to welding fumes in both work places, although to a lesser extent in the machine shops, it is difficult to attribute the excess of cancer to welding fumes only. Some other factor than welding fumes could be responsible for the found excess in shipyards. Bearing in mind the possible effect of minor differences in smoking not detected in the questionnaire study, asbestos is still the most obvious explanation, although difficult to confirm.

If one accepts the observed small excess risks of welders as real asbestos cannot be the explanation in the machine shops and is perhaps less likely also in the shipyards for the welders than for the platers. Most of the welding was performed in separate halls with no asbestos exposure, and even in the ship the welding was done mainly before the working phases which possibly involved exposure to asbestos. All in all, there seems to be about $20 \%$ excess risk of lung cancer among the welders in the present study. This is in good agreement with the average risk found in most other studies. ${ }^{19}$ Also, a register based analysis by occupations based on census information in Finland (E Pukkala, 14th International Cancer Congress, Budapest, 1986) showed a similar excess (SIR 148) for welders and flame cutters. Considering also the smoking data, this study does not exclude the possibility that welding may be associated with a small increase in lung cancer. Nevertheless, the fact that no association with follow up time could be shown makes the interpretation of the results difficult. A small increase such as this may well also be due to chance. Nevertheless, in terms of exposure to metal fumes these welders represent an extremely heavily exposed group and obviously the exposure levels in more recent times are much lower. That a significant excess of lung cancer could not be shown in a study such as this suggests that even if the risk of lung cancer were associated with welding this risk must nowadays be low, and probably too low to be unequivocally detected in most epidemiological studies.

The excess incidence of laryngeal cancer among platers in the shipyards (SIR 152) may possibly be explained by exposure to asbestos. Welding has been suspected of causing cancer of the larynx but the 
evidence in favour of this is rather weak. ${ }^{41}$ In the present study laryngeal cancer did not have have any relation with the welding exposure.

The finding of statistically significant increases in the incidence of cancer of the prostate among welders was unexpected and no explanation could be found in terms of exposure. A French study on 100 welders $^{42}$ showed two cases of prostatic cancer when only 0.6 were expected but no explanation for this finding could be presented, either. Prostatic cancer is geographically unevenly distributed in Finland, being highest in the study areas. The use of regional rates for calculating the expected values should correct most of the bias caused by this but the finding should be interpreted with caution. The aetiology of this type of cancer is obscure ${ }^{43}$ and even the suggested association with exposure to cadmium is far from clear..$^{44-47}$

The small excess of the cancer of urinary bladder among machine shop workers (SIR 132) and that of leukaemia among shipyard workers (SIR 114) were not statistically significant and had no clear relation with either duration of exposure or period of follow up. Consequently, it is difficult to consider them as related to occupational exposures.

On the whole, this study did not show any striking risk of cancer among the workers in shipyards and no overall risk in machine shops. Most of the relatively small increase in the risk of lung cancer among some groups of shipyard workers may possibly be explained by exposure to asbestos. The small increase in the risk of lung cancer found among welders is difficult to interpret in terms of exposure to metal fumes. Although it was of the same magnitude as in many other studies, it showed no clear relation with follow up time and may be due to chance.

This study has been financially supported by the Finnish Work Environment Fund.

We thank Dr Anne-Marie Bolander, MD he Swedish Statistics, and the Cancer Registries of Norway and Sweden.

\section{References}

1 Beaumont JJ, Weiss NS. Mortality of welders, shipfitters, and other metal trades workers in boilermakers local No 104,AFLCIO. Am J Epidemiol 1980;112:775-86.

2 Beaumont JJ, Weiss NS. Lung cancer among welders. $J$ Occup Med 1981;23:839-44.

3 Blot WJ, Harrington JM, Toledo A, Hoover R, Heath CW, Fraumeni JF. Lung cancer after employment in shipyard during world war II. N Engl J Med 1978;299:620-4.

4 Blot WJ, Morris LE, Stroube R, Tagnon I, Fraumeni JF. Lung and laryngeal cancers in relation to shipyard employment in coastal Virginia. J Natl Cancer Inst 1980;65:571-5.

5 Dunn JE, Linden G, Breslow L. Lung cancr mortality experience of men in certain occupations in California. $J$ Natl Cancer Inst 1980;65:571-5.
6 Gallagher RP, Threlfall WJ. Cancer mortality in metal workers. Can Med Assoc J 1983;129:1191-4.

7 Gottlieb M. Lung cancer and the petroleum industry in Louisiana. J Occup Med 1980;22:384-8.

8 McMillan GHG, Pethybridge RJ. The health of welders in naval dockyards: proportional mortality study of welders and two control groups. J Soc Occup Med 1983;33:75-84.

9 Menck HR, Henderson BE. Occupational differences in rates of lung cancer. J Occup Med 1976;18:797-801.

10 Milham S. Cancer mortality patterns associated with exposure to metals. In: Saffiotti U, Wagoner JK eds. Occupational carcinogenesis. Ann NY Acad Sci 1976;271:243-9.

11 Morton WE, Treyve ED. Histologica differences in occupational risks of lung cancer incidence. Am J Ind Med 1982;3:441-57.

12 Office of Populations Censuses and Surveys. Occupational mortality 1970-1972. England and Wales. Decennial supplement. London: HMSO, 1978.

13 Newhouse ML, Oakes D, Wooley AJ. Mortality of welders and other craftsmen at a shipyard in northeast England. $\mathrm{Br} \mathrm{J}$ Ind Med 1985;42:406-10.

14 Peterson GR, Milham Jr S. Occupational mortality in the state of California 1969-1971. Cincinnati: National Institute for Occupational Safety and Health, 1980. (NIOSH publ No 80104.)

15 Puntoni R, Vercelli M, Merlo F, Valerio F, Santi L. Mortality among shipyard welders in Genoa, Italy. Ann NY Acad Sci 1979;330:353-77.

16 Silverstein M, Maizlish N, Park R, Mirer F. Mortality among workers exposed to coal tar pitch volatiles and welding emissions: an exercise in epidemiologic triage. Am J Public Health 1985;75:1283-7.

17 Sjógren B, Hogstedt C, Malker H. Chromium and asbestos as two probable risk factors in lung cancer among welders. $J$ Occup Med 1982;24:874-5.

18 Sjögren B, Carstensen J. Cancer morbidity among Swedish welders and gas cutters. In: Stern RM, et al. eds. Health hazards and biological effects of welding fumes and gases. Amsterdam, Elsevier, 1986: 461-3. (Elsevier Biomedical Press Excerpta Medica International Congress Series 676.)

19 Peto J. Cancer morbidity and mortality studies of welders. In Stern RM, et al. eds. Health hazards and biological effects of welding fumes and gases. Amsterdam: Elsevier, 1986: 423-34. (Elsevier Biomedical Press Excerpta Medica International Congress series 676.)

20 Langard S. Confounding and effect-modifying factors in epidemiological studies in welders. In: Stern RM, et al. eds. Health hazards and biological effects of welding fumes. Amsterdam: Elsevier, 1986: 735-72. (Elsevier Biomedical Press Excerpta Medica International Congress series 676.)

21 Sunderman FW. Recent progress in nickel carcinogensis. Toxicol Environ Chem 1984;8:235-52.

22 Venit S. Genetic toxicology of chromium and nickel compounds. In: Stern RM, et al, eds. Health hazards and biological effects of welding fumes. Amsterdam: 1986: 249-66. (Elsevier Biomedical Press Excerpta Medica International Congress series 676.)

23 Fraumeni JF. Respiratory carcinogenesis: an epidemiological appraisal. J Natl Cancer Inst 1975;55:1039-46.

24 Kipling MD, Waldron HA. Polycyclic aromatic hydrocarbons in mineral oil, tar and pitch, excluding petroleum pitch. Prev Med 1976;5:262-78.

25 Sanden $\AA$. Näslund PE, Jārvholm B. Mortality in lung and gastrointestinal cancer among shipyard workers. Int Arch Occup Environ Health 1985;55:277-83.

26 Kolonel LN, YHoshizawa CN, Hirohata T, Myers BC. Cancer occurrence in shipyard workers exposed to asbestos in Hawaii Cancer Res 1985;45:3924-8.

27 Kalliomäki P-L, Alanko K, Korhonen O, Mattsson T, Vaaranen $\mathrm{V}$, Koponen M. Amount and distribution of magnetic contaminants among arc welders. Scand $J$ Work Environ Health 1978;4:122-30. 
28 Kalliomäki PL, Kalliomäki K, Korhonen O, Nordman $H$, Rahkonen E. Respiratory status of stainless steel and mild steel welders. Scand J Work Environ Health 1982;8:117-21.

29 Saxen E, Teppo L. Finnish cancer registry 1952-1977. Twenty-five years of a nationwide cancer registry. Helsinki: Finnish Cancer Registry, 1978.

30 World Health Organisation. Manual of the international statistical classification of diseases, injuries and causes of death. 7th rev. Vol 1. Geneva: WHO, 1967.

31 Rothman KJ, Boice JD Jr. Epidemiologic analysis with a programmable calculator. (NIH publ No 79-1649) Washington US, Department of Health, Education and Welfare, 1978.

32 Karvonen M, Orma E, Keys A, Fidanza F, Brozek J. Cigarette smoking, serum cholesterol, blood-pressure and body fattness. Observations in Finland. Lancet 1959;i:492-4.

33 Jāppinen P. Mortality of Finnish pulp and paper workers. Br J Ind Med 1987;44:580-7.

34 Rimpelä M. Smoking habits of the adult Finnish population in 1950 to 1970. Tampereen Yliopiston Kansanterveystieteenlaitos Tampere 1978:49-52.

35 Hakulinen T, Andersen Aa, Malker B, Pukkala E, Shou G, Tulinius $\mathbf{H}$. A collabarative study of the five Nordic cancer registries: trends in cancer incidence in the Nordic countries. Acta Pathologica Mikrobiologica et Immunologica Scandinavica. Section A. 1986;94:Suppl 288.

36 Monson RR. Observations on the healthy worker effect. J Occup Med 1986;28:425-33.

37 Tola S, Hernberg S. Healthy worker effect. In: Chiazze L, Lundin FE, Watkins D, eds. Methods and issues in occupational environmental epidemiology. Ann Arbor: Butterworth, 1984: 85-92.

38 Borgers D, Menzel R. Physicians, waitresses, welders: an analysis of smoking habits with regard to job and occupation. Munchener Medizinishe Wochenschrift 1984;126:1092-6.

39 Sterling TD, Weinkam JJ. Smoking characteristics by type of employment. J Occup Med 1986;18:743-54.

40 Jäppinen P, Tola S. Smoking among Finnish pulp and paper workers: evaluation of confounding on lung cancer and coronary heart disease rates. Scand $J$ Work Environ Health (in press).

41 Olsen J, Sabroe S, Lajers M. Welding and cancer of the larynx: a case-control study. Eur J Cancer Clin Oncol 1984;20:639-43.

42 Esnault A, Henry D, Riet D, Yhuel C. Mortality of 100 arc welders. In: Stern, et al. eds. Health hazards and biological effects of welding fumes and gases. Amsterdam: Elsevier, 1986:477-9. (Elsevier Biomedical Press Excerpta Medica International Congress series 676.)

43 Flanders WD. Review: prostate cancer epidemiology. Prostate 1984;5:621-9.

44 Armstrong BG, Kazantzis G. The mortality of cadmium workers. Lancet 1983;i:1425-7.

45 Armstrong BG, Kazantzis G. Prostatic cancer and chronic respiratory and renal disease in British cadmium workers: a case control study. Br J Ind Med 1985;42:540-5.

46 Doll R. Occupational cancer: a hazard for epidemiologists. Int $J$ Epidemiol 1985;14:22-31.

47 Elinder CG, Kjellström T, Hogstedt C, Andersson K, Spảng G. Cancer mortality of cadmium workers. $\mathrm{Br} \mathrm{J}$ Ind Med 1985;42:651-5. 